\title{
Article
}

\section{Flame Retardancy of Lightweight Sandwich Composites}

\author{
Fabienne Samyn ${ }^{1, * \mathbb{C}}$, Roland Adanmenou ${ }^{1}$, Serge Bourbigot ${ }^{1,2}$, Sophie Duquesne ${ }^{1}$, Maude Jimenez ${ }^{1,2} \mathbb{D}^{\mathbb{D}}$, \\ Marieke Van Marle ${ }^{3}$ and Sebastiaan Weij ${ }^{3}$ \\ 1 Unité Matériaux et Transformations, University Lille, CNRS, INRAE, Centrale Lille, UMR 8207-UMET, \\ F-59000 Lille, France; roland.adanmenou@univ-lille.fr (R.A.); serge.bourbigot@univ-lille.fr (S.B.); \\ sophie.duquesne@univ-lille.fr (S.D.); maude.jimenez@univ-lille.fr (M.J.) \\ 2 Institut Universitaire de France (IUF), 1 Rue Descartes, 75005 Paris, France \\ 3 Lantor, P.O. Box 45-3900, AA Verlaat 22, 3901 RG Veenendaal, The Netherlands; mmarle@lantor.com (M.V.M.); \\ sweij@lantor.com (S.W.) \\ * Correspondence: fabienne.samyn@centralelille.fr
}

Citation: Samyn, F.; Adanmenou, R.; Bourbigot, S.; Duquesne, S.; Jimenez, M.; Van Marle, M.; Weij, S. Flame Retardancy of Lightweight Sandwich Composites. J. Compos. Sci. 2021, 5, 274. https://doi.org/10.3390/ jcs5100274

Academic Editor:

Francesco Tornabene

Received: 6 September 2021

Accepted: 4 October 2021

Published: 14 October 2021

Publisher's Note: MDPI stays neutral with regard to jurisdictional claims in published maps and institutional affiliations.

Copyright: (C) 2021 by the authors Licensee MDPI, Basel, Switzerland. This article is an open access article distributed under the terms and conditions of the Creative Commons Attribution (CC BY) license (https:// creativecommons.org/licenses/by/ $4.0 /)$.

\begin{abstract}
This study proposes an innovative solution to flame-retard a sandwich composite made of unsaturated polyester resin, glass fibre skins and polyester nonwoven core material. The strategy uses the core material as flame-retardant carrier, while the resin is also flame-retarded with aluminum trihydroxide (ATH). A screening of the fire-retardant performances of the core materials, covered with different types of phosphorous flame-retardant additives (phosphate, phosphinate, phosphonate), was performed using cone calorimetry. The best candidate was selected and evaluated in the sandwich panel. Great performances were obtained with ammonium polyphosphate (AP422) at $262 \mathrm{~g} / \mathrm{m}^{2}$. The core material, when tested alone, did not ignite, and when used in the laminate, improved the fire behaviour by decreasing the peak of heat release rate (pHRR) and the total heat release (THR): the second peak in HRR observed for the references (full glass monolith and sandwich with the untreated core) was suppressed in this case. This improvement is attributed to the interaction occurring between the two FR additives, which leads to the formation of aluminophosphates, as shown using Electron Probe Micro-Analysis (EPMA), X-ray Diffraction (XRD) and solid-state ${ }^{31} \mathrm{P}$ Nuclear Magnetic Resonance (NMR). The influence of the FR add-on on the core, as well as the ATH loading in the matrix, was studied separately to optimize the material performances in terms of smoke and heat release. The best compromise was obtained using AP422 at $182 \mathrm{~g} / \mathrm{m}^{2}$ and $160 \mathrm{phr}$ of ATH.
\end{abstract}

Keywords: patterned polyester nonwoven; unsaturated polyester resin; sandwich composites; smoke toxicity; heat release

\section{Introduction}

Driven by the need to decrease the environmental impact of transportation, fibrereinforced plastics (FRP) are progressively replacing conventional materials such as aluminum or steel in this sector of applications, enabling significant weight savings and thus reducing energy consumption. As an example, for a high-speed passenger train, the energy saving is estimated at $3.2 \%$ per $10 \%$ weight reduction [1].

Among the various FRP formulations available on the market, unsaturated polyester resin (UPR)-glass fibre (GF) are widely used due to their high strength-to-weight ratio, high-quality surface finishes and good dimensional stability. The performance of these composites can be improved by the inclusion of a core material in the laminate build-up. A number of different core materials with various properties and costs are available on the market, such as thermoplastic foams, polyurethane foams or honeycomb core material. The latter are very efficient in weight reduction while maintaining the stiffness of the laminate.

However, the obtained sandwich materials not only have to present high mechanical properties, they also have to comply with other regulations, including the fire safety 
standards. In railway applications, the introduction and ratification of EN45545 leads to a unique standard to ensure the safety of people and equipment. The laminates previously described and designed for an optimized strength-to-weight ratio have to fulfil these new requirements. This target is more important for laminates including core materials than for the UPRGF composites, since the core materials are generally organic.

Solutions have been proposed in the literature to improve the fire behaviour of UPR by modifying the resin through reactive or additive routes. The first approach is generally more expensive, as it implies the synthesis of intermediate products such as prepolymers. Modifying the resin could, in some cases, lead to changes in the properties of the modified resin (thermal stability drop, viscosity increase [2], etc.). However, some patents show the great potential of resins that are modified with DOPO [3,4], phosphinic anhydride or acid [5].

The high loading of FR additives in the unsaturated polyester resin (UPR) (generally above $20 \%$ ) is another way of providing fire performances. Different solutions have been tested in the literature. These solutions were recently reviewed by Ramadan et al., who even proposed a selection chart for polyester and their fibre-fabric composite [6]. Among the most-used FR additives in UPR, aluminum trihydroxide (ATH) has been the most investigated. A recent paper by Wirawan et al. evaluated the FR effect of ATH in a 3D woven/UPR sandwich composite at different loadings [7]. The use of such fillers is generally shown to greatly impact the mechanical properties of the final parts.

The use of an insulative layer added to the surface of the sandwich composite is another approach to protect the material, which is claimed to have fewer effects on the mechanical performance of the sandwich. Different types of layer have been tested. Bourbigot et al. applied an intumescent coating layer [8], Kandare et al. chose a thin, non-woven glass veil impregnated with ammonium polyphosphate $[9,10]$, and Zhu et al. evaluated an intumescent non-woven of mineral fibres impregnated with expandable graphite [11], together with the addition of FR in the resin. Other treatment combinations have been proposed by different authors [12,13]. In these strategies, when applied to the flame retardation of a sandwich composite, the core materials are never directly treated with the FR additives.

In this study, we thus propose an innovative approach to the design of a lightweight, flame-retarded, unsaturated polyester sandwich composite, in which the core material is used as a carrier for FR additives, in combination with ATH addition in the resin (Figure 1). The core material, when impregnated with different FR additives, is first screened solely using a cone calorimeter test to enable selection. The best-performing system will be used to prepare the laminates. Our targeted application needs to fulfill Requirement 1 (R1) of the EN45545; the performances of the materials will be evaluated using cone calorimeter and smoke chamber tests. The performance will be compared to reference samples (a full glass monolithic laminate and a sandwich made with an untreated core material) and its mechanism of action will be investigated using X-ray Diffraction (XRD) and solid-state Nuclear Magnetic Resonance (NMR) analyses. Finally, the impact of a reduction in the ATH and AP422 loading and the fire performance of the composites will be investigated to optimize the proposed solution.

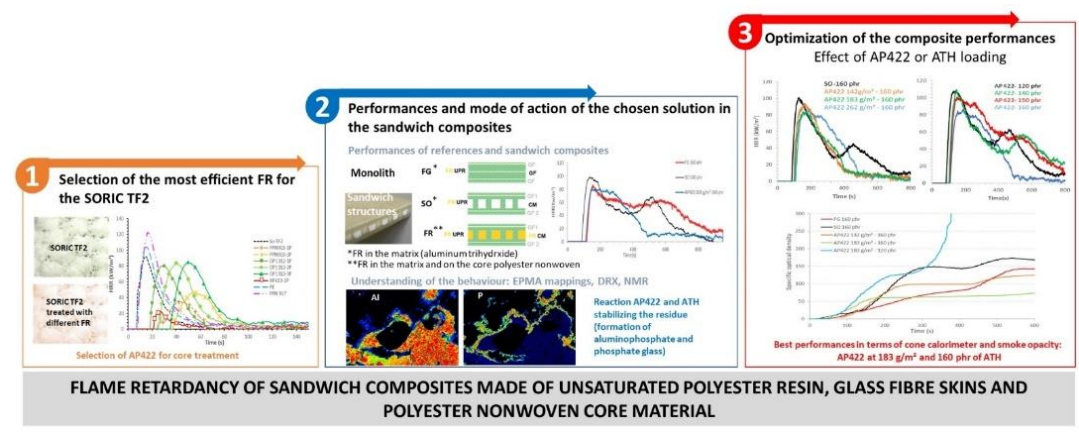

Figure 1. Graphical abstract showing the layout of the paper and main conclusions. 


\section{Materials and Methods}

\subsection{Materials}

Glass mats (GM) of different mass per area (300, 450 and $600 \mathrm{~g} / \mathrm{m}^{2}$ ) were used as a reinforcement to prepare the laminates, and SORIC TF2 (SO, $\left.125 \mathrm{~g} / \mathrm{m}^{2}\right)$, a polyester non-woven presenting a pattern (Figure 2c), was used as the core material (Lantor, Veenendaal, The Netherlands). They were dried overnight at $100{ }^{\circ} \mathrm{C}$ before use. Nordester 880 orthophtalic-based unsaturated polyester resin (UPR, Nordcomposites, Condé-Folie, France) was selected for the preparation of the composites. This resin was crosslinked using a methylethylketone peroxide (MEKP, Ketanox B180, Nordcomposite, France) as an initiator. Aluminum trihydroxide (ATH-Apyral 30X, Nabaltec AG, Schwandorf, Germany) was incorporated into the matrix as a flame-retardant. Different flame-retardants were applied on the core material (Table 1). A binder supplied by Lantor, based on a modified polycarboxylic acid and a polyol as a crosslinker, was used to immobilize these FR on the non-woven core.

a)

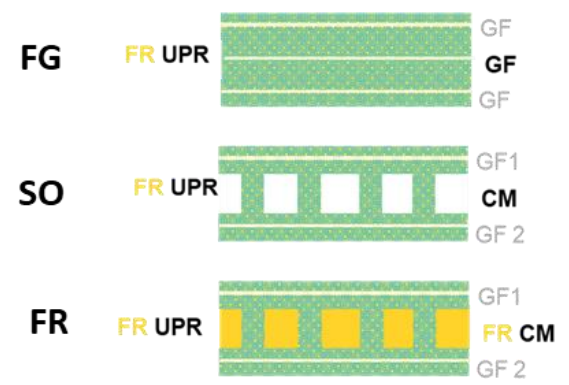

b)

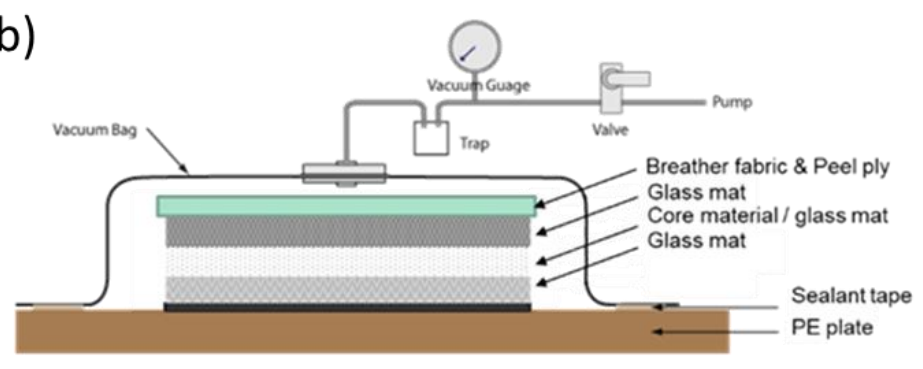

C)

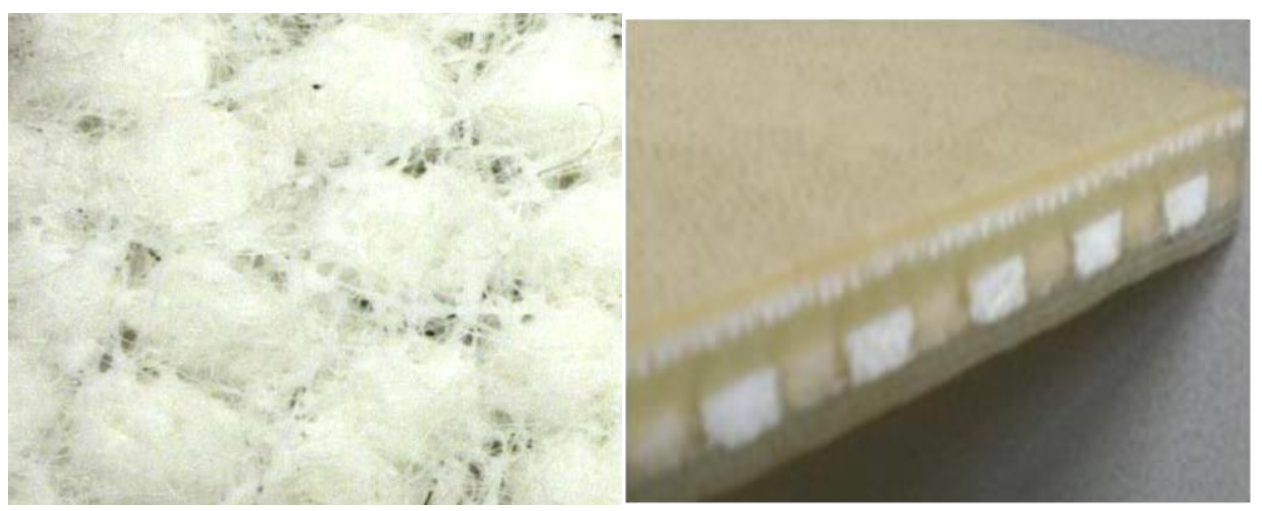

Figure 2. Schemes of (a) the build-up of the laminates and (b) the lamination process by vacuum bagging and (c) pictures of the SORIC showing its pattern and that of a composite made with it.

\subsection{Preparation of Flame Retarded Core}

The SORIC TF2 core materials were treated using a solution containing the binder, water and the flame-retardant. The treatments were carried out using a roll-padder. The samples were immersed in the solution, and placed on top of the rolls before being pressed between the rolls ( $p=0.2$ bar). Samples were prepared by one, two or three passes to adjust the FR add-on, and then cured in an oven at $100{ }^{\circ} \mathrm{C}$ until a stable mass was obtained. The SORIC was weighted before and after the treatment to determine the total add-on. As, during the curing step, the binder loses $49 \mathrm{wt} .-\%$, the binder and FR ratio in the solution used for the impregnation were assumed to be maintained at the end of the treatment. FR and binder add-ons were then calculated. We noted that, with starting solutions containing identical water, FR and binder weights, different total add-ons were obtained due to the difference in the viscosity of the obtained solution. We nevertheless chose to prepare samples with the same weights for the three ingredients. 
Table 1. Flame retardants applied on the core material.

\begin{tabular}{ccccc}
\hline Name & Commercial Name & Type of FR & Form & Supplier \\
\hline PPN917 & Aflammit PPN917 & Intumescent ester & Powder & Thor \\
PE & AFLAMMIT ${ }^{\circledR}$ PE & Cyclic phosphonate & aluminium & Clariant \\
OP1312 & Exolit OP1312 & Phosphinate, melamine polyphosphate and & Powder & \\
PPN903 & Aflammit PPN903 & $\begin{array}{c}\text { intumescent system (not based on } \\
\text { ammonium polyphosphate) }\end{array}$ & Powder & Thor \\
AP422 & Exolit AP422 & Ammonium polyphosphate & Powder & Clariant \\
\hline
\end{tabular}

\subsection{Composite Preparation}

Laminates of $30 \times 15 \mathrm{~cm}^{2}$ with different build-ups were prepared (Figure 2). The first one, used as a reference, was a monolithic structure containing only glass fibres (full glass laminate (FG)). This composite was made using two $600 \mathrm{~g} / \mathrm{m}^{2}$ glass mats and one $450 \mathrm{~g} / \mathrm{m}^{2}$ glass mat. The others were sandwich composites made using one SORIC as a core material, surrounded by one GM of $450 \mathrm{~g} / \mathrm{m}^{2}$ on one side and another of $300 \mathrm{~g} / \mathrm{m}^{2}$ on the other side. The used SORIC was either untreated or flame-retarded using the previously described protocol.

A batch of resin containing ATH was prepared in the chosen proportion, then degassed and applied with a brush on the reinforcements. The stacking was carried out on a PE plate, and then a peel ply and a breather fabric were placed on top. A vacuum bag was positioned on the stacking, maintained using sealant tape and connected to a resin trap and a pump. The resin curing took place at room temperature under vacuum for $24 \mathrm{~h}$, and then a post-curing was performed in an oven at $140^{\circ} \mathrm{C}$ for $16 \mathrm{~h}$. Samples were obtained with a thickness ranging from 4.4 to $5.1 \mathrm{~mm}$ (Table 2). It should be noted that, when using vacuum-bagging processing, it was quite difficult to control the thickness of the composites. The samples were then cut to the appropriate size to perform the different tests.

Table 2. Cone calorimeter performance of FR-treated SORIC.

\begin{tabular}{|c|c|c|c|c|c|c|c|c|c|}
\hline \multirow[b]{2}{*}{ FR Used } & \multirow[b]{2}{*}{ Type of FR } & \multirow{2}{*}{$\begin{array}{l}\text { Number } \\
\text { of Pass }\end{array}$} & \multicolumn{3}{|c|}{ Add-on $\left(\mathrm{g} / \mathrm{m}^{2}\right)$} & \multirow{2}{*}{$\begin{array}{c}\text { TTI } \\
\text { (s) }( \pm 1)\end{array}$} & \multirow{2}{*}{$\begin{array}{c}\text { PHRR } \\
\left(\mathrm{kW} / \mathrm{m}^{2}\right)\end{array}$} & \multirow{2}{*}{$\begin{array}{c}\text { THR } \\
\left(\mathrm{MJ} / \mathrm{m}^{2}\right) \\
( \pm 0.2)\end{array}$} & \multirow{2}{*}{$\begin{array}{c}\text { RW }^{3} \\
\text { (wt.-\%) } \\
( \pm 3)\end{array}$} \\
\hline & & & $\mathrm{T}^{1}$ & $\mathrm{~B}^{2}$ & FR & & & & \\
\hline$x$ & $x$ & 0 & 0 & 0 & 0 & 9 & $85 \pm 10$ & 1.9 & 32 \\
\hline PPN917 & Ester & 1 & 165 & 15 & 150 & 9 & $121 \pm 12$ & 3.0 & - \\
\hline $\mathrm{PE}$ & Phosphonate & 1 & 59 & 5 & 54 & 8 & $104 \pm 10$ & 2.5 & - \\
\hline \multirow{3}{*}{ OP1312 } & \multirow{3}{*}{$\begin{array}{l}\text { Phosphinate } \\
\text { Zinc borate }\end{array}$} & 1 & 255 & 85 & 170 & 19 & $80 \pm 8$ & 1.9 & 39 \\
\hline & & $2(-\mathrm{P} 2)$ & 340 & 113 & 227 & 31 & $84 \pm 9$ & 2.6 & 37 \\
\hline & & $3(-\mathrm{P} 3)$ & 412 & 137 & 275 & 41 & $85 \pm 9$ & 2.9 & 47 \\
\hline \multirow{2}{*}{ PPN903 } & \multirow{2}{*}{$\begin{array}{l}\text { intumescent } \\
\text { system }\end{array}$} & 1 & 283 & 94 & 189 & 25 & $35 \pm 4$ & 1.1 & 48 \\
\hline & & 3 (-P3) & 465 & 155 & 310 & 38 & $46 \pm 5$ & 1.7 & 56 \\
\hline \multirow{3}{*}{ AP422 } & \multirow{3}{*}{ polyphosphate } & 1 & 294 & 98 & 196 & 28 & $23 \pm 2$ & 0.5 & 51 \\
\hline & & $2(-\mathrm{P} 2)$ & 367 & 122 & 244 & 0 & 0 & 0 & 0 \\
\hline & & $3(-P 3)$ & 472 & 157 & 315 & 0 & 0 & 0 & 0 \\
\hline
\end{tabular}

The following nomenclature has been used in this article to describe the build-up: FG for full-glass laminate, $\mathrm{SO}$ for untreated SORIC, and FR for flame-retardant laminate. The abbreviation of the build-up is followed by the FR value add-on, given in $\mathrm{g} / \mathrm{m}^{2}$, for treated SORIC, and by the amount of ATH, given in phr. 


\subsection{Fire Testing}

A mass loss cone calorimeter was used to evaluate the fire performances of the core materials and the laminates (ISO 13927). The tests were carried out on $10 \times 10 \mathrm{~cm}^{2}$ samples exposed at $50 \mathrm{~kW} / \mathrm{m}^{2}$ and placed $25 \mathrm{~mm}$ from the cone heater using spark ignition. The specimens were wrapped in a single layer of aluminum foil. The peak in heat release rate (PHRR), the total heat release (THR), time to ignition (TTI), and maximum of average heat release (MAHRE) were the parameters extracted from the curve and used to compare the behaviour of the materials.

A home-made smoke box was used to obtain the smoke density. This instrument presents the same conception as the NBS chamber (inner dimension: L $914 \mathrm{~mm}, \mathrm{H} 914 \mathrm{~mm}$, D $610 \mathrm{~mm}$ ) and the same heat source, but the instrumentation is different. A smoke density analyser TRDA 302 from Taurus was used. The light is emitted using a halogen point light-source of intensity $\mathrm{I}_{0}$ and the transmitted light of intensity I is measured by a Silicon photoreceiver. Samples of $75 \times 75 \mathrm{~mm}^{2}$ were exposed to the conical radiative heater, placed at $23 \mathrm{~mm}$ horizontally, delivering $50 \mathrm{~kW} / \mathrm{m}^{2}$. No pilot flame was used to ignite the sample.

The fire-testing methodology used to evaluate our composites was limited to the tests that are mentioned for the R1 of the ENS45545, i.e., cone calorimeter and smoke test chamber, even if a full fire-behaviour investigation was required to make additional fire evaluations. It should be noted that in our results, the values obtained from the tests cannot be directly compared to the ones given in the EN45545, since our testing apparatus are not the ones used in the standards. Indeed, we used a mass loss cone calorimeter in which the heat released was measured via a thermopile instead of oxygen consumption, and the smoke opacity was not measured using the standardized opacimeter.

\subsection{Other Characterizations}

Electron Probe Microscopic Analyser (EPMA) was used to observe the dispersion of the FR additives in the composites and residues. They were carried out on a CAMECA SX100. The samples were carbon-coated with a Bal-Tec SCD005 sputter-coater prior to analysis. Phosphorus, silicon and aluminum $X$-ray mappings were carried out at $15 \mathrm{kV}$ and $40 \mathrm{nA}$. Images are color-coded, with red representing a high concentration of the analyzed element and black representing a low concentration of the analyzed element.

Chemical characterizations were carried out to identify the reaction products between the component of the materials. $X$ ray diffraction analyses were performed using a $\mathrm{SmartLab}^{\odot}$ Rigaku diffractometer (Rigaku, Tokyo, Japan) equipped with a $9 \mathrm{~kW}$ rotating anode X-ray generator $(\mathrm{Cu} \mathrm{K} \alpha=1.5418 \mathrm{~A})$, fitted with a DTEX one-dimensional silicon-strip detector, in Bragg-Brentano reflection geometry. The $\theta-2 \theta$ scans were performed in the range $5-80^{\circ}$, with a step size of $0.03^{\circ}$ and a speed of $2^{\circ} / \mathrm{min}$.

${ }^{31} \mathrm{P}$ NMR analyses of the samples containing phosphorous were performed to observe the eventual modifications to the phosphorous environment resulting from interactions/degradation during the fire exposure. The measurements were performed on a Bruker Advance II 400 at $40.5 \mathrm{MHz}$ using a $4 \mathrm{~mm}$ probe, with dipolar decoupling (DD) and magic angle spinning (MAS) at a speed of $12.5 \mathrm{kHz}$. The delay time between two impulsions was fixed at $60 \mathrm{~s}$. The spectra were acquired as a result of 16 scans. The reference used was $85 \% \mathrm{H}_{3} \mathrm{PO}_{4}$ in aqueous solution.

\section{Results}

\subsection{FR Efficiency on the SORIC TF2}

SORIC TF2 was first treated solely with different FR additives and exposed to mass loss cone calorimeter test, to select the most efficient FRs for later incorporation in the laminate. Table 2 and Figure 3 present the composition of the flame-retarded SORIC in terms of total, FR and binder add-ons, as well as the data (TTI, PHRR and THR) obtained from the cone calorimeter. Phosphate, phosphonate, phosphinate and intumescent blends were evaluated, and their performances were compared to those of untreated SORIC TF2. 


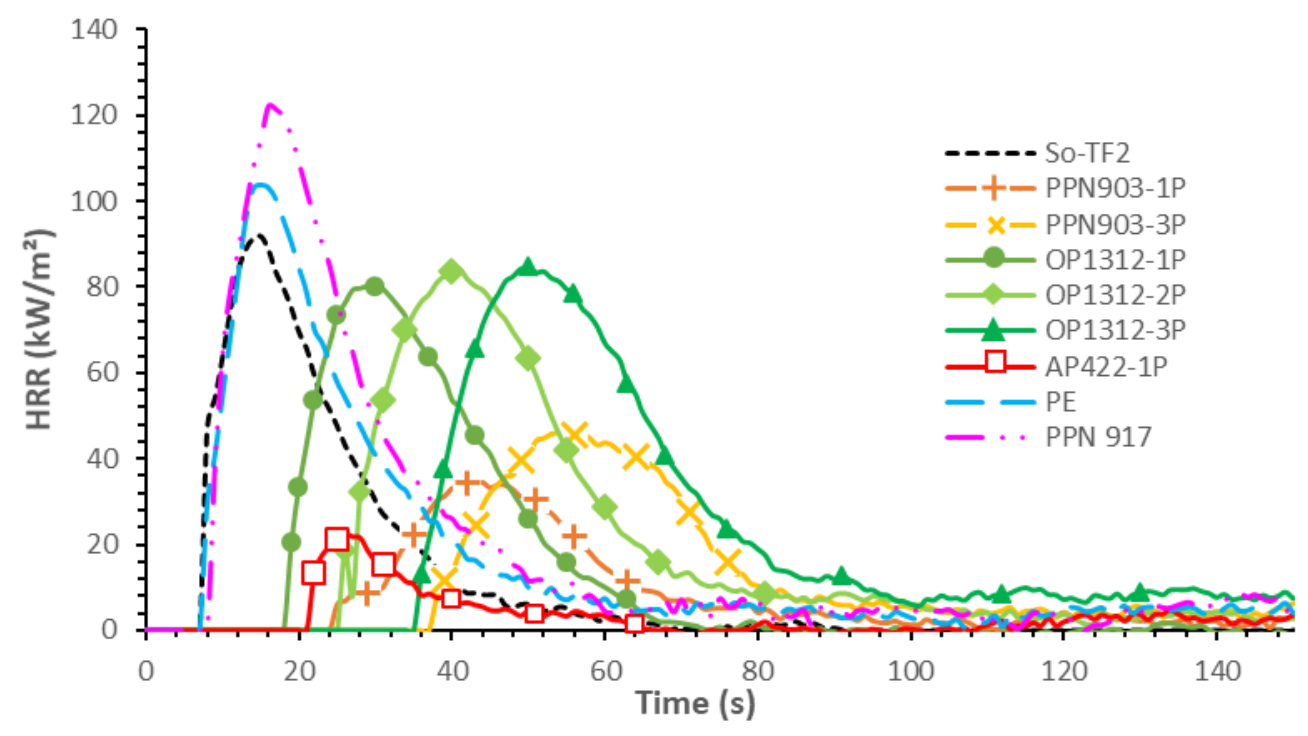

Figure 3. HRR curves of SORIC flame retarded with different additives.

Untreated SORIC TF2 ignites after $9 \mathrm{~s}$ and burns under the cone heater, reaching up to $85 \mathrm{~kW} / \mathrm{m}^{2}$ and a total of $1.9 \mathrm{MJ} / \mathrm{m}^{2}$. The samples, when treated once by the FR solutions (one pass samples), presented FR add-ons of around 150-200 g/ $\mathrm{m}^{2}$, except when PE (liquid) additive was used for the treatment, for which the add-on was much lower $\left(54 \mathrm{~g} / \mathrm{m}^{2}\right)$. These samples can be classified into three groups according to their performances. PPN917 and PE, i.e., phosphate esters and phosphonate, respectively, constituted the first group. Their behaviour was globally worse than the untreated sample. They led to the same or higher PHRRs (121 and $\left.104 \mathrm{~kW} / \mathrm{m}^{2}\right)$, higher THRs (3 and $2.5 \mathrm{MJ} / \mathrm{m}^{2}$ ) and unchanged TTIs (8 s) compared with the untreated sample. Then, the OP1312 sample (phosphinate) was in the second group, where the performances slightly improved. This treatment has no effect on the PHRR and THR, however; the TTI increased from 9 to 19 s. Finally, the last group was composed of the intumescent treatments, i.e., PPN903 and AP422. Both additives significantly improved the SORIC properties. In both cases, the PHRR, the THR and the TTI were beneficially impacted, with AP422 being the most efficient (the lowest PHRR and THR and longest TTI).

Additional samples were prepared with OP1312, PPN903 and AP422 by repeating the impregnation process two or three times to increase the amount of FR that was deposited on the SORIC. Loadings of $230 \mathrm{~g} / \mathrm{m}^{2}$ for two passes $(-2 \mathrm{P})$, and $300 \mathrm{~g} / \mathrm{m}^{2}$ for three passes, $(-3 P)$ were obtained. According to the cone data, such FR loadings do improve the fire behaviour of OP1312- and PPN903-treated samples. For OP1312, the PHRR remains the same whatever the FR uptake, whereas, for PPN903, it increases slightly. In addition, with increased add-on, higher THR values were achieved because of the increase in the binder amount and, consequently, in flammable content. However, the TTI was improved in both cases and the higher the loading, the higher the TTI. For AP422, however, the samples that were impregnated two and three times with the solution do not ignite at all.

These differences in fire behaviour can be related to the mode of action of the tested FR. Similar behaviour has already been reported for phosphinate in the literature. Alongi et al. [14]. studied the efficiency of sol-gel coatings containing aluminum phosphinate at different loadings for the treatment of cotton fibres, and observed a slight increase in the PHR and the TTI with increased loadings. Didane et al. [15] evaluated the effect of polyurethane back-coatings containing aluminum phosphinate on PET fabric and obtained similar results. In both cases, the phosphinate leads to a thermal destabilization of the coating, which induces an early decomposition and promotes the formation of a carbonization layer, protecting the substrate. When this layer fails, the underlying material degrades entirely, leading to a high PHRR. The carbonization is limited with phosphinate compared to PPN903 and AP422, as evidenced by the residual weight of the samples after 
the cone test. For the intumescent systems based on PPN903 or AP422, the condensed phase action related to the micro-intumescence [16] occurring on the non-woven samples can both delay the ignition and also efficiently shield the subtract, leading to a lower PHRR, incomplete combustion and enabling more residue to remain. With AP422, both gas phase and condensed phase actions take place (dilution of the flammable gases with ammonia, intumescence with the binder), which could explain the better fire properties that were obtained [17]. As AP422 was most efficient FR (whatever the loading), it was selected to prepare the FR laminates.

\subsection{Evaluation of Laminates Made Using AP422 Treated SORIC TF2}

Full-glass laminates and sandwich composites made with untreated SORIC and AP422 $262 \mathrm{~g} / \mathrm{m}^{2}$ treated SORIC were prepared using the UPR containing $160 \mathrm{phr}$ of ATH. The cross-sections of the samples were observed using EPMA, and elemental X-ray mappings were carried out to highlight the presence of glass fibres (Si element), ATH (Al element) and AP422 (P element) (Figure 4). In the FG laminate, the glass fibres are clearly detectable using Si X-ray mapping, and the presence of ATH in the matrix is also clearly evidenced by Al mapping.

Fullglass laminate (FG)
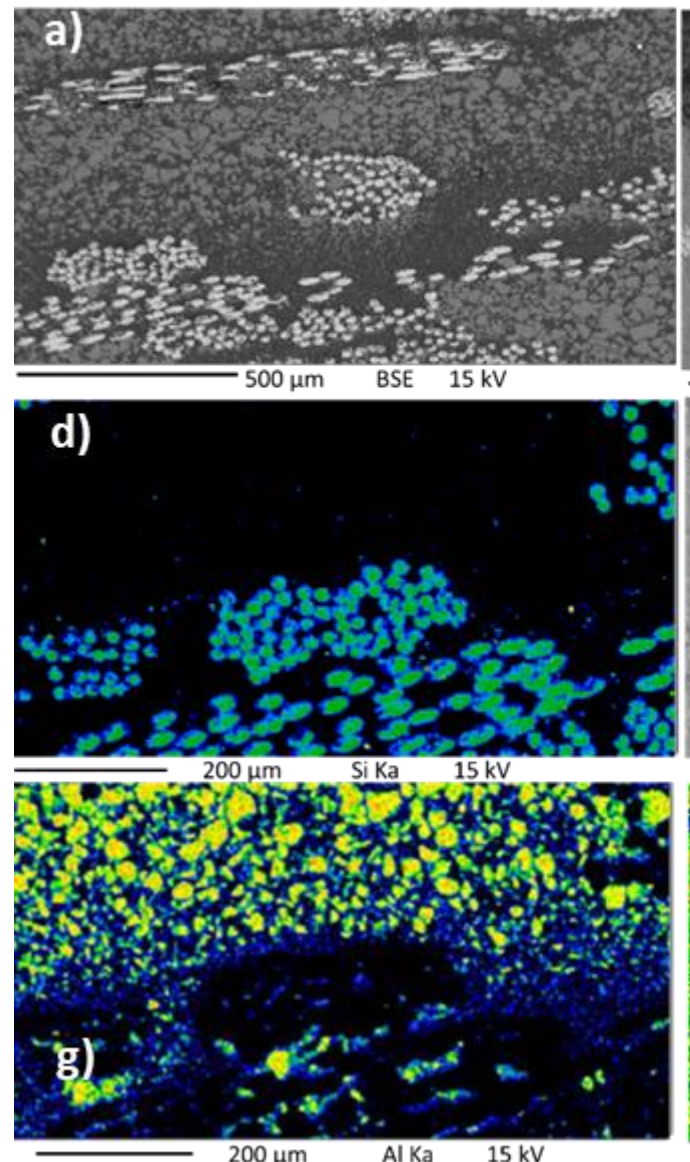

SORIC laminate (SO)
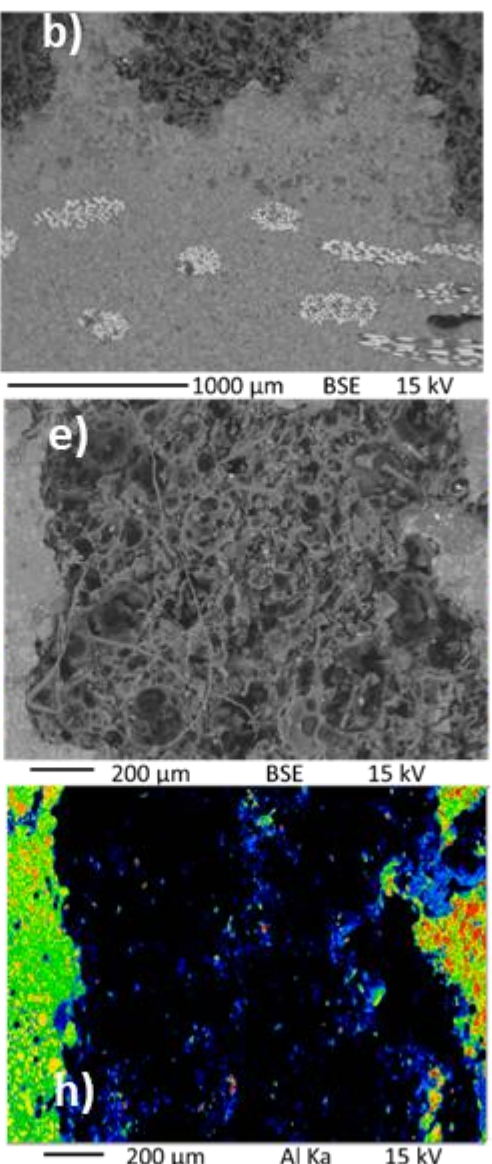

AP422 laminate (FR)
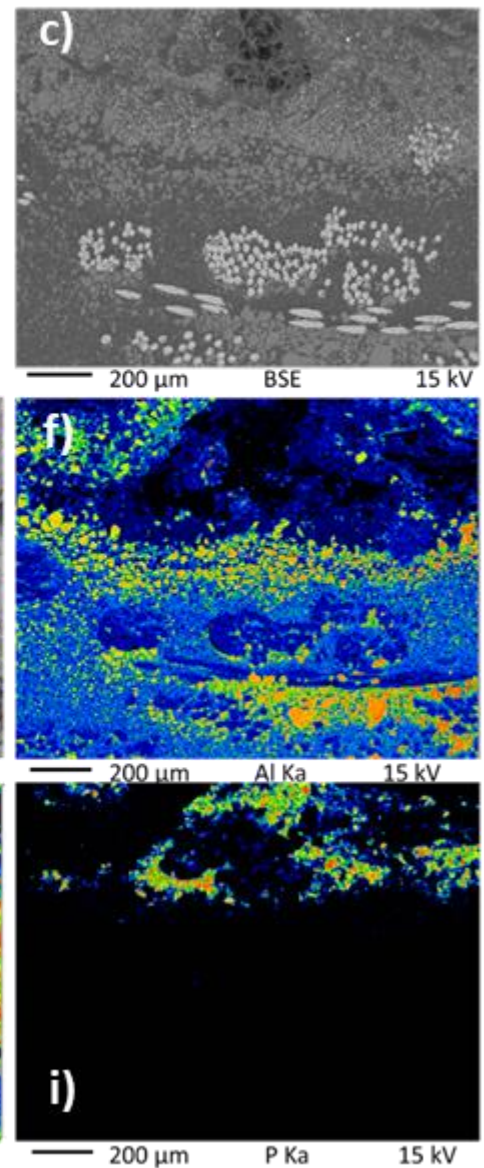

Figure 4. BSE pictures and elemental mappings of the different laminates obtained from EPMA. The first column concerns the full-glass laminate and provides (a) the BSE picture, (d) the Si and (g) the Al mapping. The second column shows the characterization of the untreated SOIRC sandwich with (b) showing a BSE picture of the interface between the core material and the glass skin, (e) showing a BSE picture of a pattern of the SORIC that is not filled by the resin and (h) showing the corresponding Al mapping. In the third column, the data are from the laminate containing AP422-treated SORIC. (c) presents the BSE picture of the interface of the treated SORIC and the glass skin, (f) the corresponding Al mapping and (i) the corresponding P mapping. 
For the composite containing the untreated SORIC, the first picture shows the interface between the glass layer and the SORIC layer. Glass fibres and the patterns of the SORIC can be observed. The patterns, made of fibres and holes, are not filled in with the resin, and they consequently do not contain any ATH, as evidenced by the Al mapping. For the AP422-treated SORIC, the observed pattern is not totally visible because the cross-section cut was performed close to its surface. However, it is still clear that the presence of $\mathrm{Al}$ and $\mathrm{P}$ can be observed in the resin and on the pattern, respectively.

The fire behaviour of these laminates was then evaluated using the mass-loss calorimeter. The curves obtained for each sample are presented in Figure 5 and the data in Table 3. Full-glass laminates ignite after $120 \mathrm{~s}$ exposure. The heat release reaches a maximum of $82 \mathrm{~kW} / \mathrm{m}^{2}$ soon after ignition, before decreasing gradually to reach a minimum at $400 \mathrm{~s}$, and then slightly rising to a second maximum of around $55 \mathrm{~kW} / \mathrm{m}^{2}$ at $600 \mathrm{~s}$. After $600 \mathrm{~s}$, the HRR decreases again due to the extinction of the material. The introduction of an untreated SORIC core material to the laminate is detrimental to the fire performance of the material. Compared to FG laminates, the TTI is decreased to $87 \mathrm{~s}$, the PHRR is slightly higher $\left(96 \mathrm{~kW} / \mathrm{m}^{2}\right)$, and the second peak in HRR occurs earlier and is of a similar intensity as the FG samples, although the THR is significantly reduced from 37 to $24 \mathrm{MJ} / \mathrm{m}^{2}$. This may result from the decrease in the UPR resin content of the composite. The core material indeed ensures that less UPR is contained in the structure.
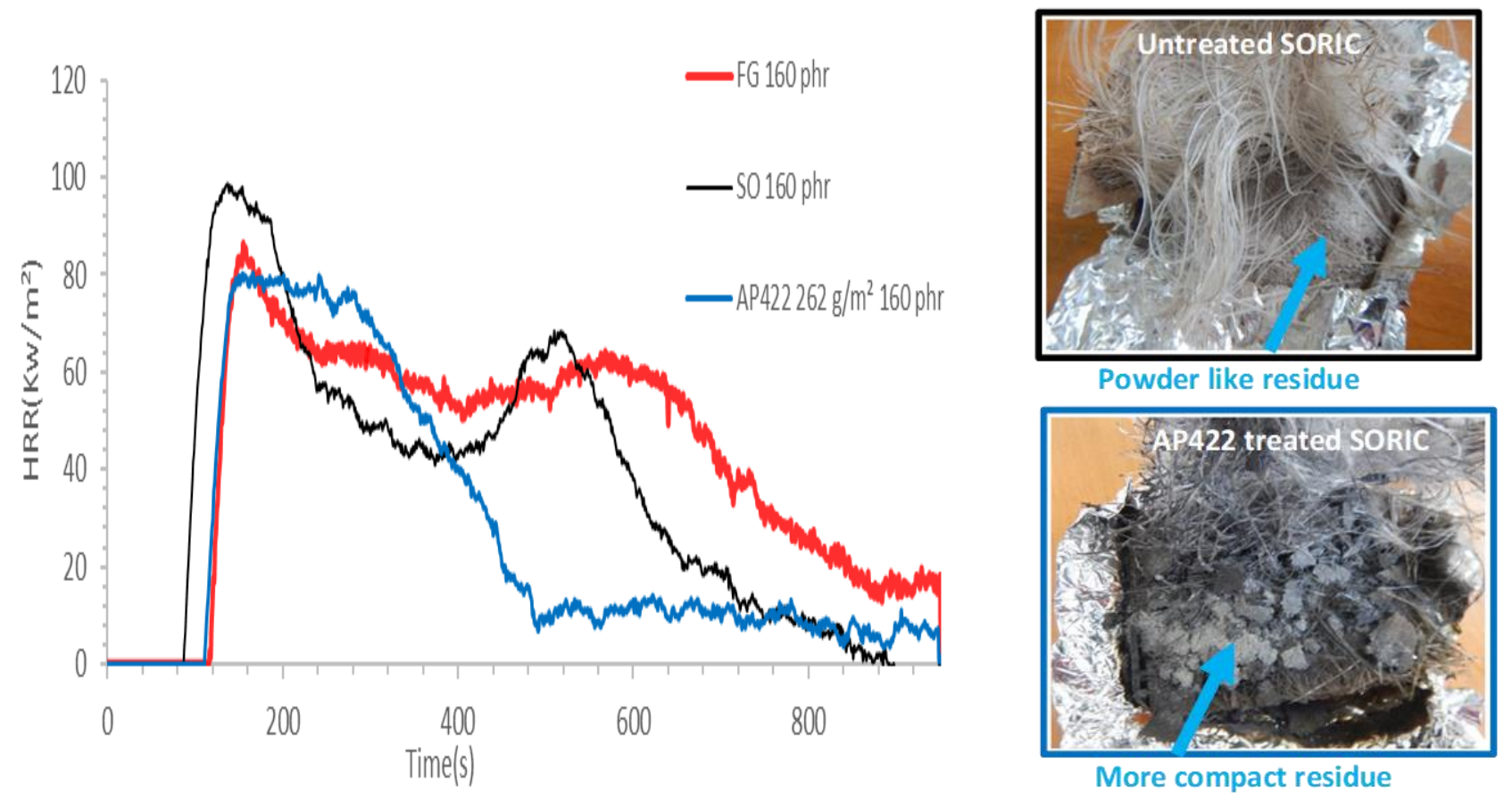

Figure 5. Cone calorimeter curves of the full-glass laminates, the untreated and AP422-treated SORIC TF2 sandwich composites made with $160 \mathrm{phr}$ of ATH in the UPR and pictures of the residues obtained at the end of the test.

When the SORIC is treated with APP, the behaviour is modified. Contrary to the first two samples, the curve exhibits a single peak. The obtained PHRR and TTI are equivalent to that for FG. The presence of FR treatment in the SORIC is, consequently, efficient and leads to a suppression of the second peak in HRR and a quick flame-out of the sample. This leads to a reduced THR $\left(25 \mathrm{MJ} / \mathrm{m}^{2}\right)$ compared to the FG laminate $\left(37 \mathrm{MJ} / \mathrm{m}^{2}\right)$.

Pictures of the residues of the SORIC-containing laminates obtained after the fire tests are presented in Figure 4. The first layer, containing the glass fibres, was removed to observe the middle layer, containing the SORIC. Differences can be observed between the two residues. Without treatment, the middle layer appears as a powder consisting of aluminum oxide, resulting from the decomposition of the ATH-filled UP resin. However, 
when the SORIC is treated with AP422, this middle layer is more preserved and compact, suggesting a stabilization of the residue.

Table 3. Parameters extracted from the cone calorimeter data obtained for the different laminates.

\begin{tabular}{|c|c|c|c|c|c|c|c|c|c|c|}
\hline \multirow{2}{*}{ Name } & \multirow{2}{*}{$\underset{(\mathrm{mm})}{\mathrm{e}^{1}}$} & \multirow{2}{*}{$\begin{array}{l}\text { ATH } \\
\text { (phr) }\end{array}$} & \multicolumn{3}{|c|}{ Add-on $\left(\mathrm{g} / \mathrm{m}^{2}\right)$} & \multirow{2}{*}{$\begin{array}{l}\text { TTI } \\
\text { (s) }\end{array}$} & \multirow{2}{*}{$\begin{array}{c}\text { PHRR } \\
\left(\mathrm{kW} / \mathrm{m}^{2}\right)\end{array}$} & \multirow{2}{*}{$\begin{array}{l}\text { MAHRE } \\
\left(\mathrm{kW} / \mathrm{m}^{2}\right)\end{array}$} & \multirow{2}{*}{$\begin{array}{c}\text { THR } \\
\left(\mathrm{MJ} / \mathrm{m}^{2}\right)\end{array}$} & \multirow{2}{*}{$\begin{array}{c}\text { RW } \\
\text { (wt.-\%) }\end{array}$} \\
\hline & & & $T^{2}$ & $B^{3}$ & FR & & & & & \\
\hline FG $160 \mathrm{phr}$ & $4.6 \pm 0.1$ & 160 & - & - & - & $120 \pm 3$ & $82 \pm 2$ & $66 \pm 1$ & $37 \pm 2$ & $58 \pm 1$ \\
\hline SO $160 \mathrm{phr}$ & $4.5 \pm 0.2$ & 160 & - & - & - & $87 \pm 3$ & $96 \pm 4$ & $80 \pm 2$ & $24 \pm 4$ & $54 \pm 1$ \\
\hline $\begin{array}{c}\mathrm{AP} 422262 \mathrm{~g} / \mathrm{m}^{2} \\
160 \mathrm{phr}\end{array}$ & $5.2 \pm 0.1$ & 160 & 288 & 26 & 262 & $97 \pm 2$ & $85 \pm 5$ & $71 \pm 3$ & $25 \pm 2$ & $56 \pm 1$ \\
\hline $\begin{array}{c}\mathrm{AP} 422183 \mathrm{~g} / \mathrm{m}^{2} \\
160 \mathrm{phr}\end{array}$ & $5.0 \pm 0.1$ & 160 & 190 & 7.6 & 183 & $103 \pm 3$ & $81 \pm 3$ & $70 \pm 2$ & $18 \pm 3$ & $57 \pm 1$ \\
\hline $\begin{array}{c}\mathrm{AP} 422142 \mathrm{~g} / \mathrm{m}^{2} \\
160 \mathrm{phr}\end{array}$ & $5.0 \pm 0.1$ & 160 & 150 & 7.5 & 142 & $100 \pm 3$ & $92 \pm 3$ & $78 \pm 2$ & $19 \pm 3$ & $55 \pm 1$ \\
\hline $\begin{array}{c}\text { AP422 } 240 \mathrm{~g} / \mathrm{m}^{2} \\
150 \mathrm{phr}\end{array}$ & $5.1 \pm 0.1$ & 150 & 264 & 24 & 240 & $104 \pm 2$ & $103 \pm 3$ & $88 \pm 1$ & $38 \pm 3$ & $52 \pm 1$ \\
\hline $\begin{array}{c}\text { AP422 } 229 \mathrm{~g} / \mathrm{m}^{2} \\
140 \mathrm{phr}\end{array}$ & $4.7 \pm 0.1$ & 140 & 252 & 23 & 229 & $101 \pm 2$ & $107 \pm 3$ & $86 \pm 5$ & $37 \pm 3$ & $54 \pm 1$ \\
\hline $\begin{array}{c}\text { AP422 } 205 \mathrm{~g} / \mathrm{m}^{2} \\
120 \mathrm{phr}\end{array}$ & $4.4 \pm 0.1$ & 120 & 225 & 20 & 205 & $82 \pm 3$ & $104 \pm 4$ & $83 \pm 7$ & $31 \pm 4$ & $51 \pm 1$ \\
\hline
\end{tabular}

${ }^{1} \mathrm{e}=$ thickness, ${ }^{2} \mathrm{~T}=$ total,$~^{3} \mathrm{~B}=$ binder, ${ }^{4} \mathrm{RW}=$ residual weight.

3.3. Discussion on the Mechanistic Insight into the Improvement of the Performances with AP422 Coated SORIC

To understand the performance obtained with the AP422-coated SORIC, different analyses were performed. Firstly, using EPMA, $\mathrm{Al}$ and $\mathrm{P}$ mappings were carried out on the residue obtained from the cone calorimeter (Figure 6). At first, zones rich in $\mathrm{P}$ or $\mathrm{Al}$ are clearly detected. By looking most closely at the mappings, it also appears that $\mathrm{P}$ and $\mathrm{Al}$ are both present in the same location but in different proportions: Al-rich zones contain a low proportion of $\mathrm{P}$ and vice versa. Consequently, it seems that ATH and AP422 interact together during burning.

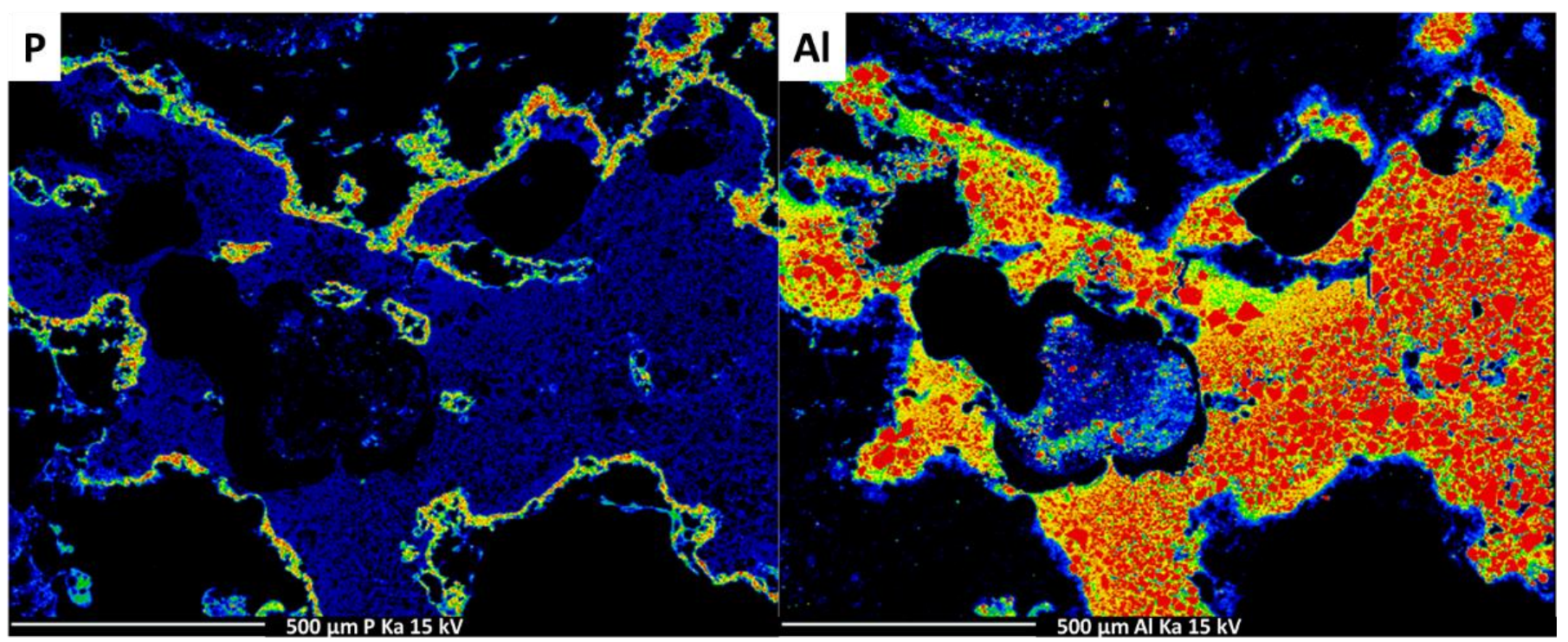

Figure 6. $\mathrm{P}$ and $\mathrm{Al}$ mapping in the AP422 SORIC laminate residue obtained after the cone calorimeter test. 
To identify the nature of these interactions, $\mathrm{XRD}$ and ${ }^{31} \mathrm{P}$ solid-state NMR analyses were performed on the residue (Figure 7). XRD analysis shows the presence of decomposition products of ATH such as aluminum oxide and boehmite (identified using the database), as well as the presence of aluminosphosphate (identified according to a previous study) [18]. ${ }^{31} \mathrm{P}$ NMR confirms the presence of this species. The spectrum of raw aluminophosphate indeed fits one of the peaks (around $-30 \mathrm{ppm}$ ) in the spectrum. Other peaks are detected that have not been identified yet. The presence of aluminophosphate indicates a reaction between AP422 and ATH. Such a reaction has already been reported in the literature [19]. This reaction can stabilize the residue in the solid phase and form a more effective char layer. In addition, the presence of a large band between -50 and $10 \mathrm{ppm}$ is detected, revealing the presence of amorphous phosphate species. This phosphate glass could also be beneficial for the cohesion of the residue. These characterizations consequently show that different products are formed during the combustion of the samples, which all contribute to the performances of the materials. This FR sandwich is even more efficient due to the presence of the chemical interaction occurring at the interface of the treated core material/filled resin.
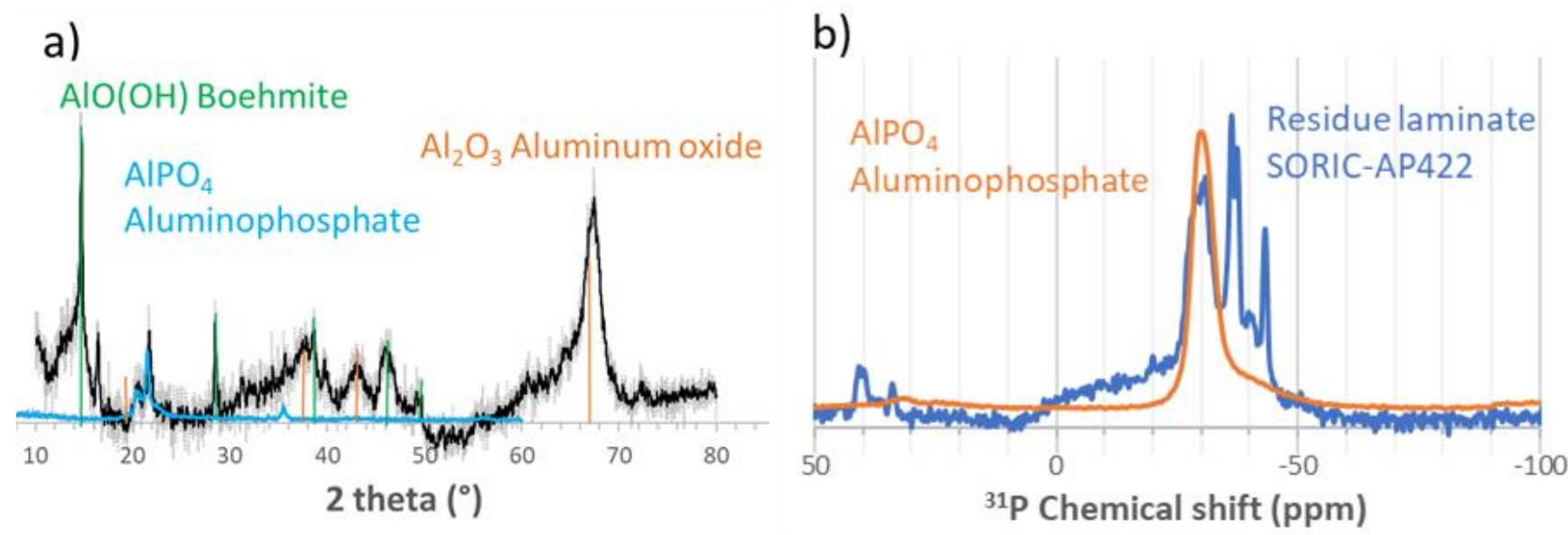

Figure 7. XRD analyses (a) and ${ }^{31} \mathrm{P}$ NMR spectrum (b) of AP422 SORIC laminate residue.

\subsection{Optimization of the System}

Different approaches to optimizing the FR materials' processability and weight without losing fire performance have been explored. The first one consists of studying the influence of the FR add-on on the fire performances of the composite and the second one consists of keeping the FR add-on constant while decreasing the ATH loading.

The HRR curves of the composites made with SORIC treated with 142, 183 or $262 \mathrm{~g} / \mathrm{m}^{2}$ of AP422 are presented on Figure 8 and compared with the curve of the untreated SORIC. Data are gathered in Table 2. The treatment, whatever the add-on, can increase the TTI to around $100 \mathrm{~s}$ compared to $80 \mathrm{~s}$. In addition, in all cases, the second peak, observed without any treatment, is suppressed. The effect of the addition of THR and PHRR is not obvious. The THRs with $142 \mathrm{~g} / \mathrm{m}^{2}$ and $183 \mathrm{~g} / \mathrm{m}^{2}$ are equal. For the sample containing AP422 $262 \mathrm{~g} / \mathrm{m}^{2}$-ATH $160 \mathrm{phr}$, the THR is higher than those of the two other treated materials, due to the resin content used to fix the AP422 on the SORIC (i.e., about $26 \mathrm{~g} / \mathrm{m}^{2}$ compared to about $7.5 \mathrm{~g} / \mathrm{m}^{2}$ for the other samples). It appears that applying between 142 and $183 \mathrm{~g} / \mathrm{m}^{2}$ of AP422 to the SORIC, while limiting the quantity of resin used to fix it, is beneficial for both the weight and processability of the composite and can ensure satisfactory fire performances. 

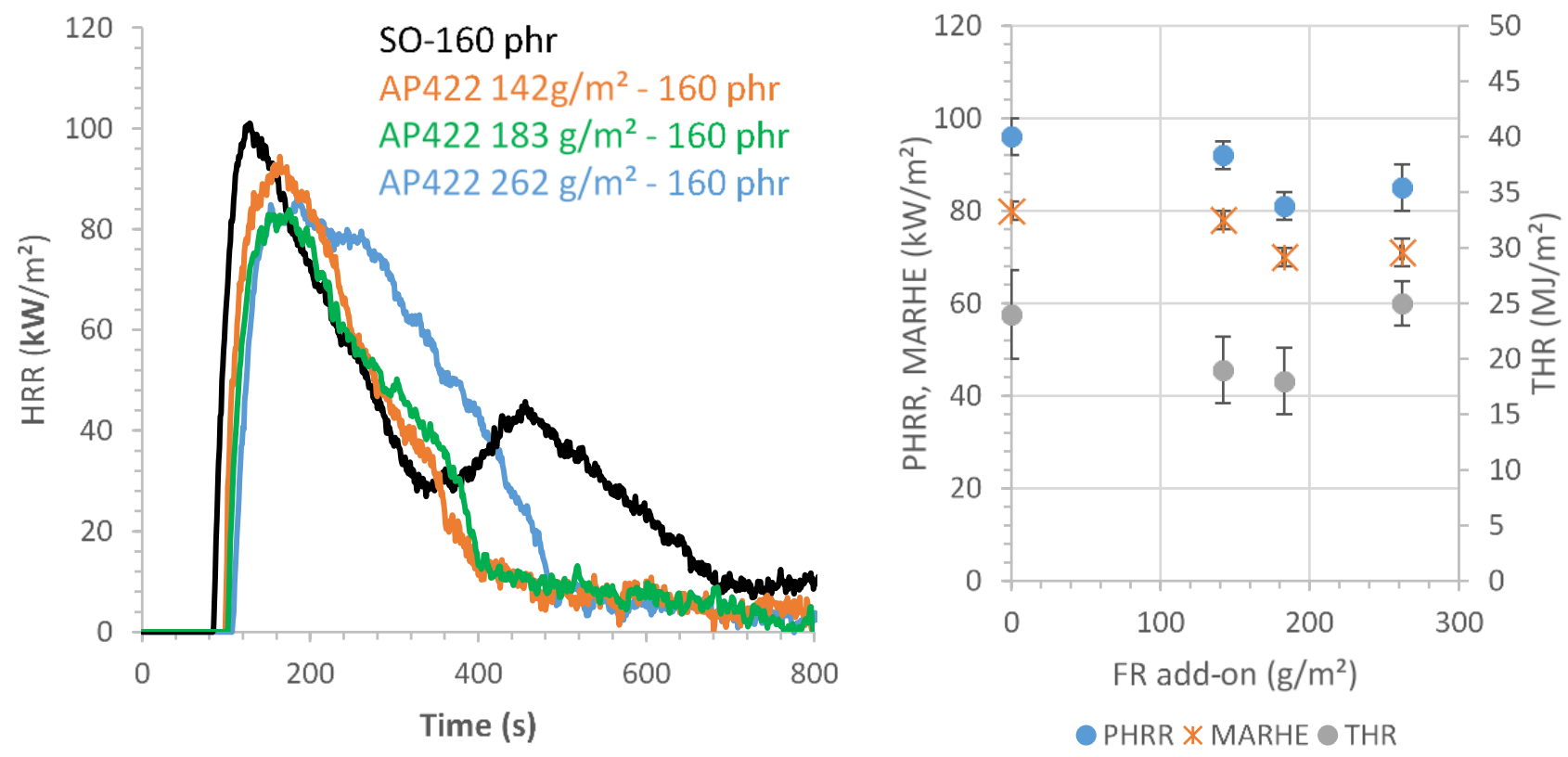

Figure 8. HRR curves of composites made using AP422-treated SORIC with different add-ons and evolution of some of the cone parameters versus the FR add-on.

To confirm the interest in decreasing the FR add-on, FG, SO and AP422 183 and $142 \mathrm{~g} / \mathrm{m}^{2}$ samples were evaluated in terms of smoke opacity, using the home-made smoke chamber test.

The curves showing the specific opacity versus time are presented in Figure 9. Both the FG and the SORIC-containing sandwiches present curves with two smoke release steps (the first between 0 and $425 \mathrm{~s}$, and another occurring at the end of the experiment). However, the negative effect of introducing the SORIC to the composite in terms of smoke is evidenced by the higher opacity values obtained for this material over the duration of the experiment (maxima of opacity at 172 for SO and 143 for FG). This negative effect can, however, be counter-balanced by the AP422 treatment of the nonwoven. For this material (AP422 $183 \mathrm{~g} / \mathrm{m}^{2}-160 \mathrm{phr}$ ), a plateau is reached from $150 \mathrm{~s}$ at an opacity value of 70 . This sandwich material releases slightly more smoke than the FG sample, but only up to $270 \mathrm{~s}$, making it very interesting.

To investigate the effect of ATH-loading on the fire performances of treated composites, samples were prepared using the same add-on (around $230 \mathrm{~g} / \mathrm{m}^{2}$ ) and ATH, dispersed in the UPR at 120, 140, 150 and 160 phr. Figure 10 presents the HRR curves obtained for these samples, as well as the evolution of some cone parameters versus ATH loading. The ATH loading has a great influence on the fire behaviour of the samples. As soon as the ATH loafing is decreased below $160 \mathrm{phr}$, the shape of the curve changes, with the reappearance of a second peak, and the samples exhibit equivalent PHRR, THR and MARHE. The decrease in the ATH amount is thus detrimental to the fire properties in terms of PHRR and THRR. The same conclusion can be derived by looking at the results of the smoke opacity measurements (Figure 8). The results of the samples treated with the same FR add-on and either 120 or $160 \mathrm{phr}$ of ATH in the resin are very contrasted. With $120 \mathrm{phr}$ of $\mathrm{ATH}$, the sample releases much more smoke, leading, after $350 \mathrm{~s}$, to the saturation of the light detector. With decreases in the ATH content, the amount of UPR increases; this can explain the increased smoke generation. 


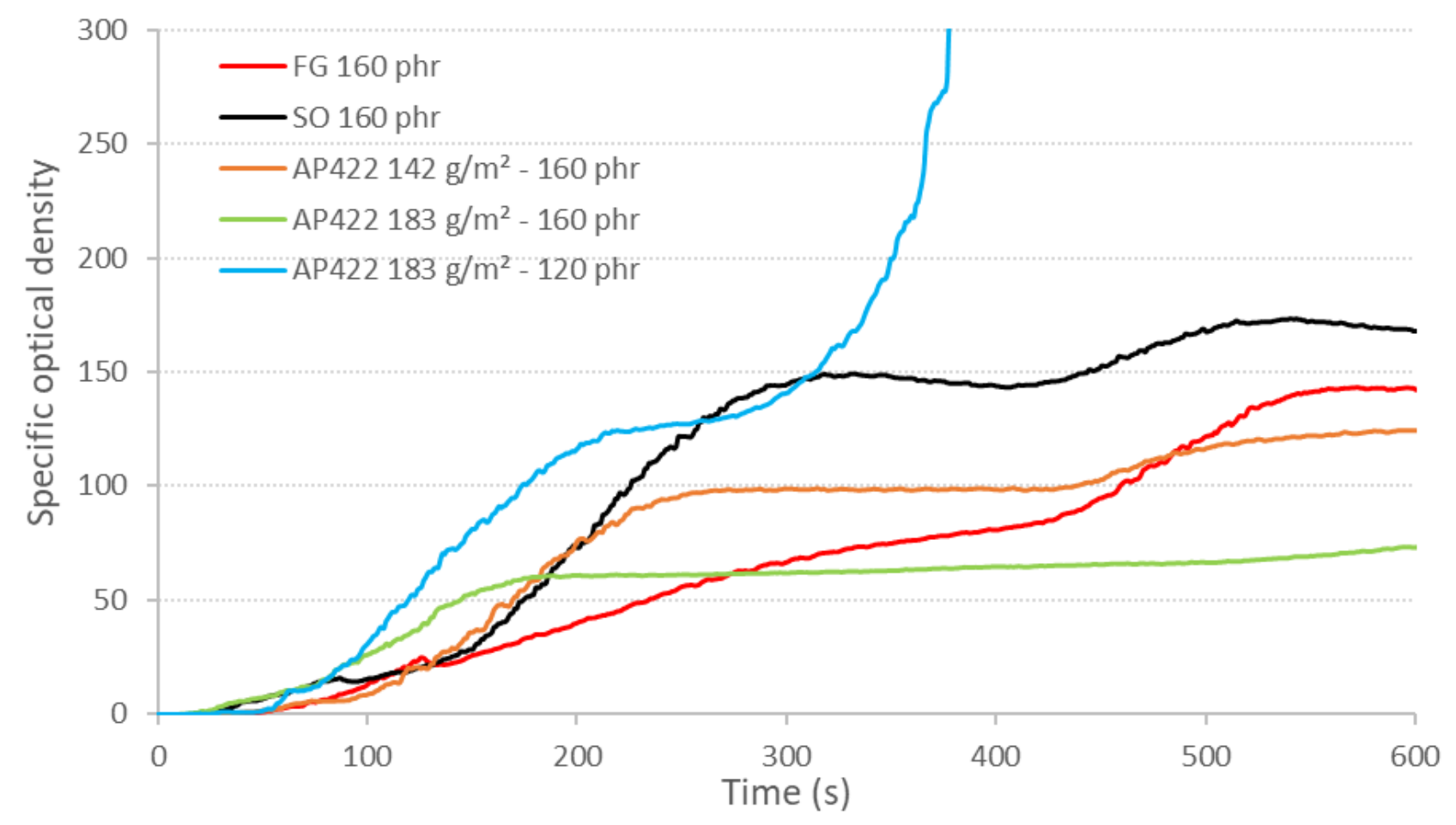

Figure 9. Specific optical density curves of the laminates.
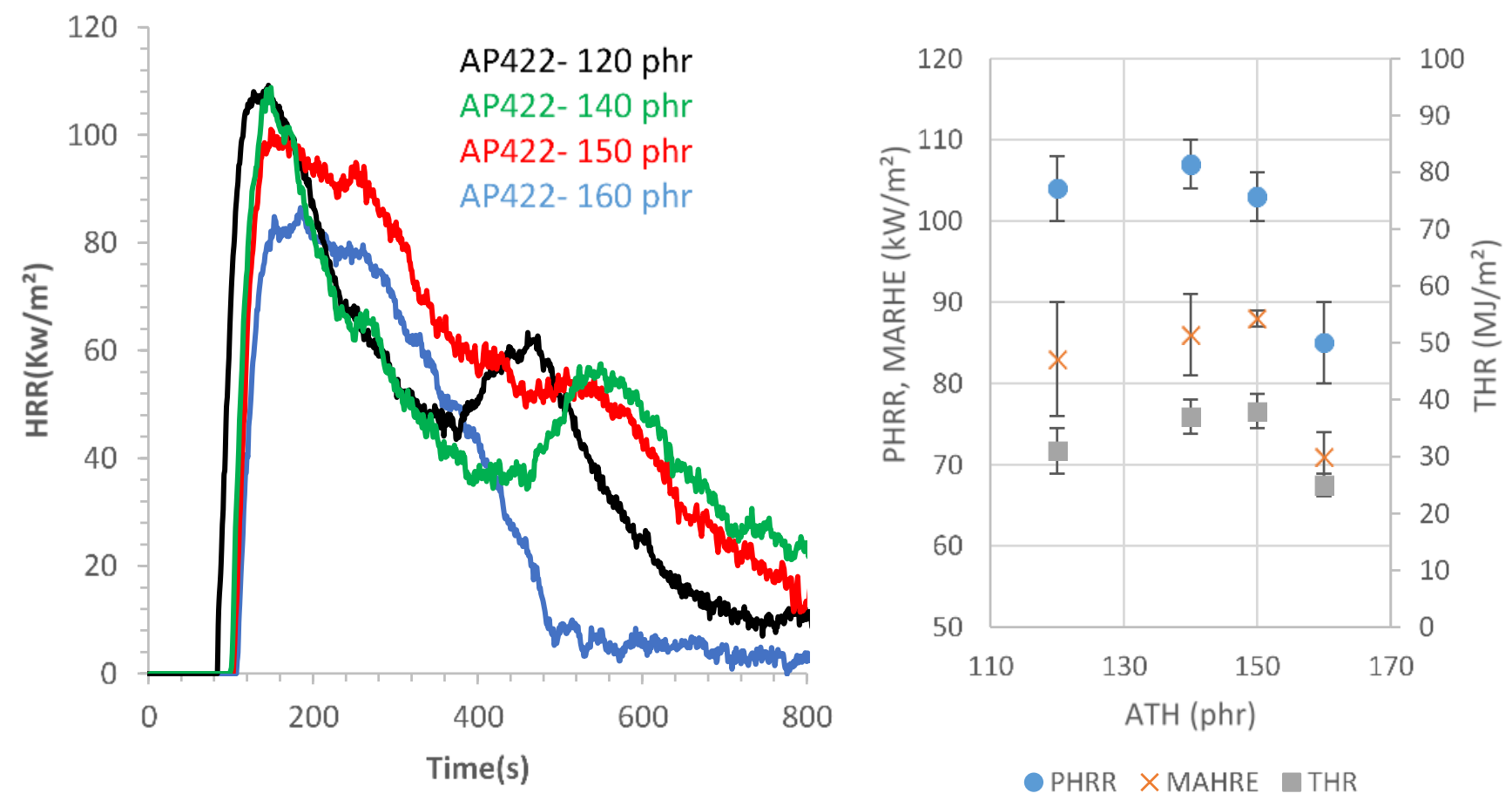

Figure 10. HRR curves of the composites made using APP-treated SORIC (add-on around $230 \mathrm{~g} / \mathrm{m}^{2}$ ) and UPR resins containing different ATH loadings, and evolution of some of the cone parameters versus the ATH loading.

According to the different results presented above, the best compromise between the flame-retardant add-on, the ATH loading, the fire performances, the smoke production and the processability is the sandwich made using AP422 $\left(183 \mathrm{~g} / \mathrm{m}^{2}\right)$-treated SORIC and $160 \mathrm{phr}$ of ATH in the UP resin. 


\section{Conclusions}

The preparation of a flame-retarded sandwich composites using a specific core material made of a non-woven patterned polyester was investigated. The selected approach used this core material as a carrier of FR additives in addition to the use of ATH in the unsaturated polyester matrix. Ammonium polyphosphate was selected from different types of phosphorous FR additives as the most efficient option, based on cone calorimeter results. When applied at $262 \mathrm{~g} / \mathrm{m}^{2}$ on the core materials, it prevents their ignition. Its use in the sandwich modified the burning behaviour by suppressing the second peak of heat release that was observed for the sandwich made using the untreated core material. Ammonium polyphosphate and aluminum trihydroxide interact with each other, leading to the formation of aluminophosphates that stabilize the residue. Optimizations of the AP422 and ATH loadings were investigated. It was proven that reducing the AP422 add-on to $183 \mathrm{~g} / \mathrm{m}^{2}$ on the non-woven core is possible while maintaining the FR performances. However, further reducing the add-on leads to more smoke generation. Additionally, the ATH loading of the resin could not be reduced below $160 \mathrm{phr}$ without strongly decreasing the fire performances.

Author Contributions: Conceptualization, F.S., M.J. and S.D.; methodology, F.S., M.J., S.D., M.V.M and S.W.; formal analysis, R.A.; investigation, R.A.; data curation, R.A.; writing-original draft preparation, F.S.; writing-review and editing, F.S., M.J., M.V.M. and S.B.; supervision, F.S., M.J., S.D., S.B. and M.V.M.; project administration, M.J.; funding acquisition, M.V.M. and S.W. All authors have read and agreed to the published version of the manuscript.

Funding: This research was funded by the company Lantor.

Acknowledgments: The authors thank the electron probe microanalyser (EPMA) facility of Lille (France) that is supported by the European Regional Development Fund (ERDF).

Conflicts of Interest: The authors declare no conflict of interest.

\section{References}

1. European Standard. EN 45545. Railway Applications-Fire Protection on Railway Vehicles-Part 2: Requirements for Fire Behavior of Materials and Component; European Committee for Standardization (CEN): Brussels, Belgium, 2013.

2. Cheng, Y.-N.; Chang, S.-J.; Sheen, Y.-C.; Juang, S.-P. Process for Preparing Flame-Retardant Phosphorus-Containing Unsaturated Polyester. U.S. Patent 5,571,888A, 5 November 1996.

3. Bauer, M.; Just, B. Prepolymers Containing Phosphororganic Compounds and Uses Thereof. U.S. Patent 20,060,223,921A1, 5 October 2006.

4. Zhang, C.; Huang, J.Y.; Liu, S.M.; Zhao, J.Q. The Synthesis and Properties of a Reactive Flame-Retardant Unsaturated Polyester Resin from a Phosphorus-Containing Diacid. Polym. Adv. Technol. 2011, 22, 1768-1777. [CrossRef]

5. Hörold, S.; Schmitz, H.-P. Flame-Retardant Unsaturated Polyester Resins. U.S. Patent 6,639,017B1, 28 October 2003.

6. Ramadan, N.; Taha, M.; La Rosa, A.D.; Elsabbagh, A. Towards Selection Charts for Epoxy Resin, Unsaturated Polyester Resin and Their Fibre-Fabric Composites with Flame Retardants. Materials 2021, 14, 1181. [CrossRef] [PubMed]

7. Wirawan, R.; Judawisastra, H.; Taufiq, D.I. Development of a Fire-Retardant 3-Dimensional Woven Glass-Polyester Sandwich Composite. AIP Conf. Proc. 2020, 2262, 030012. [CrossRef]

8. Bourbigot, S.; Bachelet, P.; Samyn, F.; Jimenez, M.; Duquesne, S. Intumescence as Method for Providing Fire Resistance to Structural Composites: Application to Poly (Ethylene Terephtalate) Foam Sandwich-Structured Composite. Compos. Interfaces 2013, 20, 269-277. [CrossRef]

9. Kandare, E.; Luangtriratana, P.; Kandola, B.K. Fire Reaction Properties of Flax/Epoxy Laminates and Their Balsa-Core Sandwich Composites with or without Fire Protection. Compos. Part B Eng. 2014, 56, 602-610. [CrossRef]

10. Kandare, E.; Modica, P.D.; Chevali, V.S.; Gibson, G.A. Evaluating the Heat Resistance of Thermal Insulated Sandwich Composites Subjected to a Turbulent Fire. Fire Mater. 2016, 40, 586-598. [CrossRef]

11. Zhu, C.; Li, S.; Li, J.; Clement, M.; Rudd, C.; Yi, X.; Liu, X. Fie Performance of Sandwich Composites with Intumescent Mat Protection: Evolving Thermal Insulation, Post-Fire Performance and Rail Industry Testing. Fire Saf. J. 2020, 116, 103205. [CrossRef]

12. Dietenberger, M.A.; Shalbafan, A.; Welling, J.; Boardman, C. Treated and Untreated Foam Core Particleboards with Intumescent Veneer: Comparative Analysis Using a Cone Calorimeter. J. Therm. Anal. Calorim. 2013, 114, 979-987. [CrossRef]

13. Wang, C.; Chen, M.; Yao, K.; Zhu, X.; Fang, D. Fire Protection Design for Composite Lattice Sandwich Structure. Sci. Eng. Compos. Mater. 2017, 24, 919-927. [CrossRef]

14. Alongi, J.; Ciobanu, M.; Malucelli, G. Novel flame retardant finishing systems for cotton fabrics based on phosphorus-containing compounds and silica derived from sol-gel processes. Carbohydr. Polym. 2011, 85, 599-608. [CrossRef] 
15. Didane, N.; Giraud, S.; Devaux, E. Fire performances comparison of back coating and melt spinning approaches for PET covering textiles. Polym. Degrad. Stab. 2012, 97, 1083-1089. [CrossRef]

16. Jimenez, M.; Guin, T.; Bellayer, S.; Dupretz, R.; Bourbigot, S.; Grunlan, J. Microintumescent mechanism of flame-retardant water-based chitosan-ammonium polyphosphate multilayer nanocoating on cotton fabric. J. Appl. Polym. Sci. 2016, $133,43783$. [CrossRef]

17. Drevelle, C.; Duquesne, S.; Le Bras, M.; Lefebvre, J.; Delobel, R.; Castrovinci, A.; Magniez, C.; Vouters, M. Influence of ammonium polyphosphate on the mechanism of thermal degradation of an acrylic binder resin. J. Appl. Polym. Sci. 2004, 94, 717-729. [CrossRef]

18. Samyn, F.; Bourbigot, S. Thermal Decomposition of Flame Retarded Formulations PA6/Aluminum Phosphinate/Melamine Polyphosphate/Organomodified Clay: Interactions between the Constituents? Polym. Degrad. Stab. 2012, 97, 2217-2230. [CrossRef]

19. Castrovinci, A.; Camino, G.; Drevelle, C.; Duquesne, S.; Magniez, C.; Vouters, M. Ammonium Polyphosphate-Aluminum Trihydroxide Antagonism in Fire Retarded Butadiene-Styrene Block Copolymer. Eur. Polym. J. 2005, 41, 2023-2033. [CrossRef] 